\title{
CRANIOMETRIC DIFFERENTIATION \\ OF THE EUROPEAN BROWN HARE (Lepus europaeus PALLAS 1778) ACROSS DIFFERENT HABITATS IN SERBIA
}

\author{
Svetlana M. Milošević-Zlatanović* and Marija J. Jovanović \\ University of Kragujevac, Faculty of Science \\ Radoja Domanovića 12, 34000 Kragujevac, Serbia \\ *Corresponding author; E-mail: svetlanamz@kg.ac.rs
}

(Received March 26th, 2019; Accepted May 4th, 2019)

\begin{abstract}
The European brown hare (Lepus europaeus Pallas, 1778) is very important game species distributed across Europe. We tested the hypothesis that the populations of the European brown hare from five localities in Serbia differ significantly in size and shape of the cranium. Craniometric analysis based on 21 craniometric measurements was performed on the 71 skulls and mandibles from five localities: Čelarevo (18 individuals, intermediate habitats), Novi Sad (6 individuals, open habitats), Ada (6 individuals, open habitats), Stragari (21 individuals, closed habitats) and Knić (20 individuals, closed habitats). Analysis of variance, principal component analysis and canonical discriminant analysis were used to analyze craniometic measurements. We expected different levels of cranial variability in closed habitats which are characterized by stable and predictable (more homogenous) environments, intermediate habitats, and in open habitats which are characterized by unstable, fluctuating (more heterogeneous) environments. The results showed partial grouping of populations in accordance with the habitat type (open, closed and intermediate). Both populations from closed habitats (Stragari and Knić) had smaller skulls. However, when observing intermediate and open habitats, lesser differences existed, especially between individuals from Čelarevo (intermediate habitat) and Novi Sad (open habitat). The observed differences are probably the result of adaptations to diverse environmental conditions at different habitat types. These preliminary results suggest that differentiation of populations in accordance with habitat type does exist in European brown hare, and further analyses on greater sample size and number of populations are needed to understand the influence of habitat conditions on cranial variability of this species.
\end{abstract}

Keywords: European brown hare, Lepus europaeus, craniometric variability, population differentiation.

\section{INTRODUCTION}

The European brown hare (Lepus europaeus Pallas, 1778) is very important game species distributed across Europe. It inhabits both lowland and upland areas, especially regions with intense agricultural activities (THOMPSON, 2010). The most suitable habitats for European brown hare are patchy crop fields with grain and grasses, but it can also be found 
close to forest and steppe vegetation (NowAK, 1999). Recently, the size of its populations declined along the entire distribution range, including Serbia (VAPA and ŠELMIĆ, 1997; DANILOVIĆ and GAČIĆ, 2014). Main causes of the declining numbers are the enhancement of agricultural fields and loss of patchy areas, predators, pesticides, diseases, poaching and unregulated introductions and reintroductions (WINCENTZ JENSEN, 2009). Additionally, the taxonomy of the European brown hare is not well defined, with different authors describing different subspecies at the same distribution areas (see FLUX and ANGERMAN, 1990; HOFFMAN and SMITH, 2005; BoudET, 2010). The only taxonomic revision of the European brown hare populations from Serbia was done by MARTINO (1935) who suggested that populations from Romania to Peloponnese belong to the subspecies Lepus europaeus transsylvanicus Matschie, 1901. Thus, declining population numbers and the lack of information on their taxonomic status make the European brown hare the priority species for investigation and conservation.

Bearing in mind the impact of habitat change on the decline of population size of the European brown hare, we explored the impact of different habitat types on cranial variability. Mammalian cranium is a good model for the investigation of habitat impact on morphological traits, as it is strongly influenced by natural selection and evolution (KOYABU et al., 2014). In Lagomorpha, changes in cranial skeleton, such as differences in facial region and auditory bullae, are influenced by social and foraging behavior and predator avoidance, which are mainly determined by habitat type (GE et al., 2015). Craniometric analyses of the species from the genus Lepus were done by many authors, including CABOŃ-RACZYŃSKA (1964a, 1964b), PAlacios (1996), SlAmeČKA et al. (1997), Riga et al. (2001), SHEVCHENKo and Peskov (2005), PAlacios et al. (2008), Pintur et al. (2014), DEMirbaş and AlabyraK (2014) in Europe, HIRAKAWA et al. (1992), XIN (2003) and YOM-TOV and GEFFEN (2006) in Asia, and BAKER et al. (1978) and NAGORSEN (1985) in North America. However, although European brown hare is one of the most common and intensively hunted game species in Serbia, there are no studies of craniometric differentiation of European brown hare populations.

We tested the hypothesis that the populations of the European brown hare from five localities in Serbia differ significantly in size and shape of the cranium. We expected different levels of cranial variability in closed habitats which are characterized by stable and predictable (more homogenous) environments, intermediate habitats, and in open habitats which are characterized by unstable, fluctuating (more heterogeneous) environments, especially in terms of food and shelter availability and higher predation stress.

\section{MATERIALS AND METHODS}

\section{Sample collection}

For this study, a total of 71 skulls and mandibles of adult European brown hare were collected from five localities in Serbia (Fig. 1) - Čelarevo (18 individuals), Novi Sad (6 individuals), Ada (6 individuals), Stragari (21 individuals) and Knić (20 individuals). Samples from different localities were assigned to one of the three habitat categories, based on the percentage of major habitat and foraging types (MiLOŠEVIĆ-ZlatANOVIĆ et al., 2016). The open habitats (Novi Sad and Ada) presented the first category which included localities with predominantly agricultural landscapes, meadows and grasslands $(>80 \%)$. Closed habitats (Stragari and Knić) included localities situated in temperate and montane forests $(>30 \%$ continuous forest). Intermediate habitats (Čelarevo) included the remaining localities with larger proportions of forested areas in comparison with open habitats and which are frequently 
present as complex, patchy and heterogeneous ecotonal habitats and wood/field ecotones as basic foraging areas. In total 21 cranial measurements were recorded with a dial caliper to the nearest $0.01 \mathrm{~mm}$. The craniometric measurements (Fig. 2) were chosen to capture most of the cranial morphology.

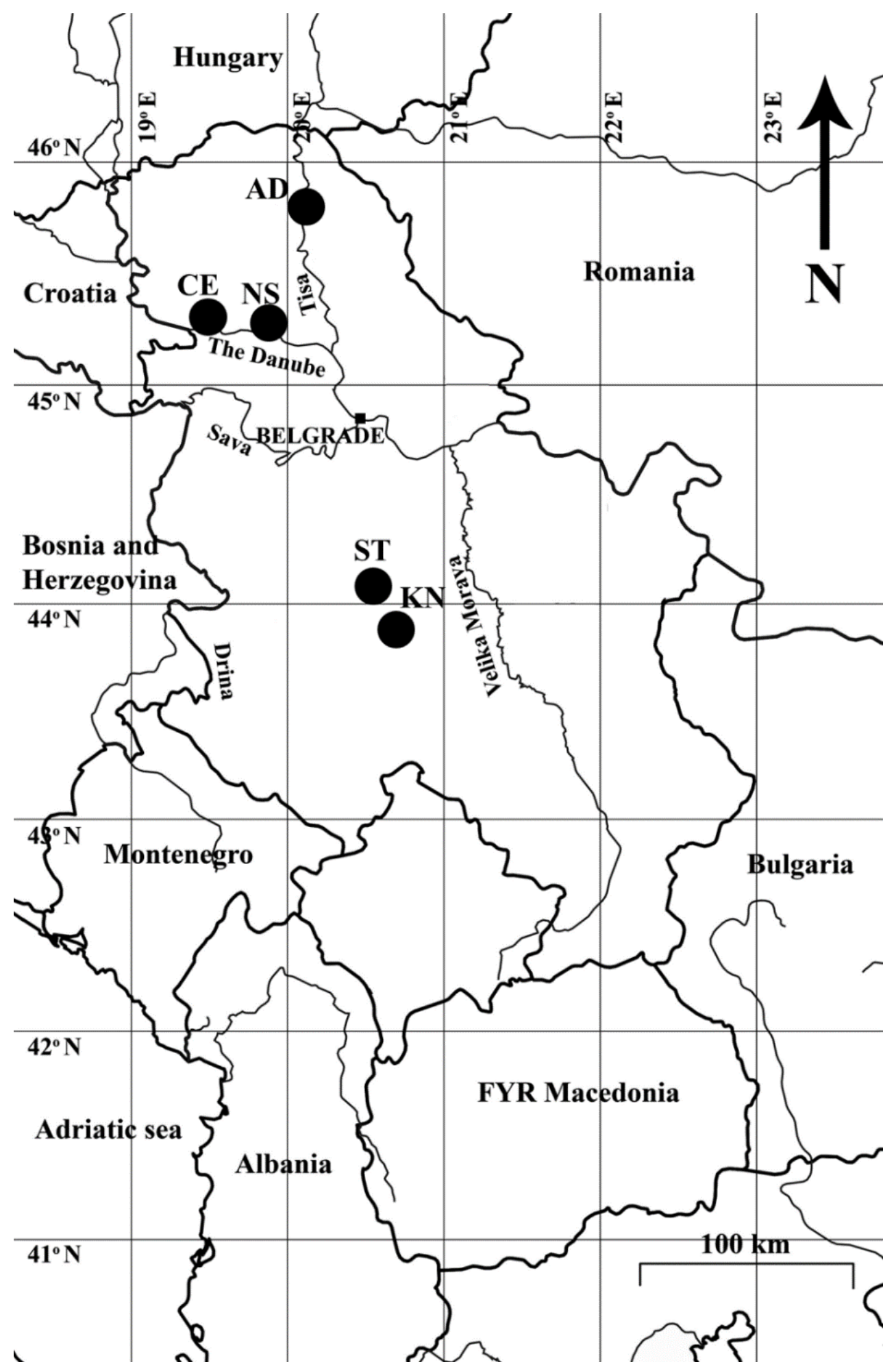

Figure 1. Map of five sampling localities in Serbia. Abbreviations: CE - Čelarevo; NS - Novi Sad; AD - Ada; ST - Stragari; KN - Knić. 


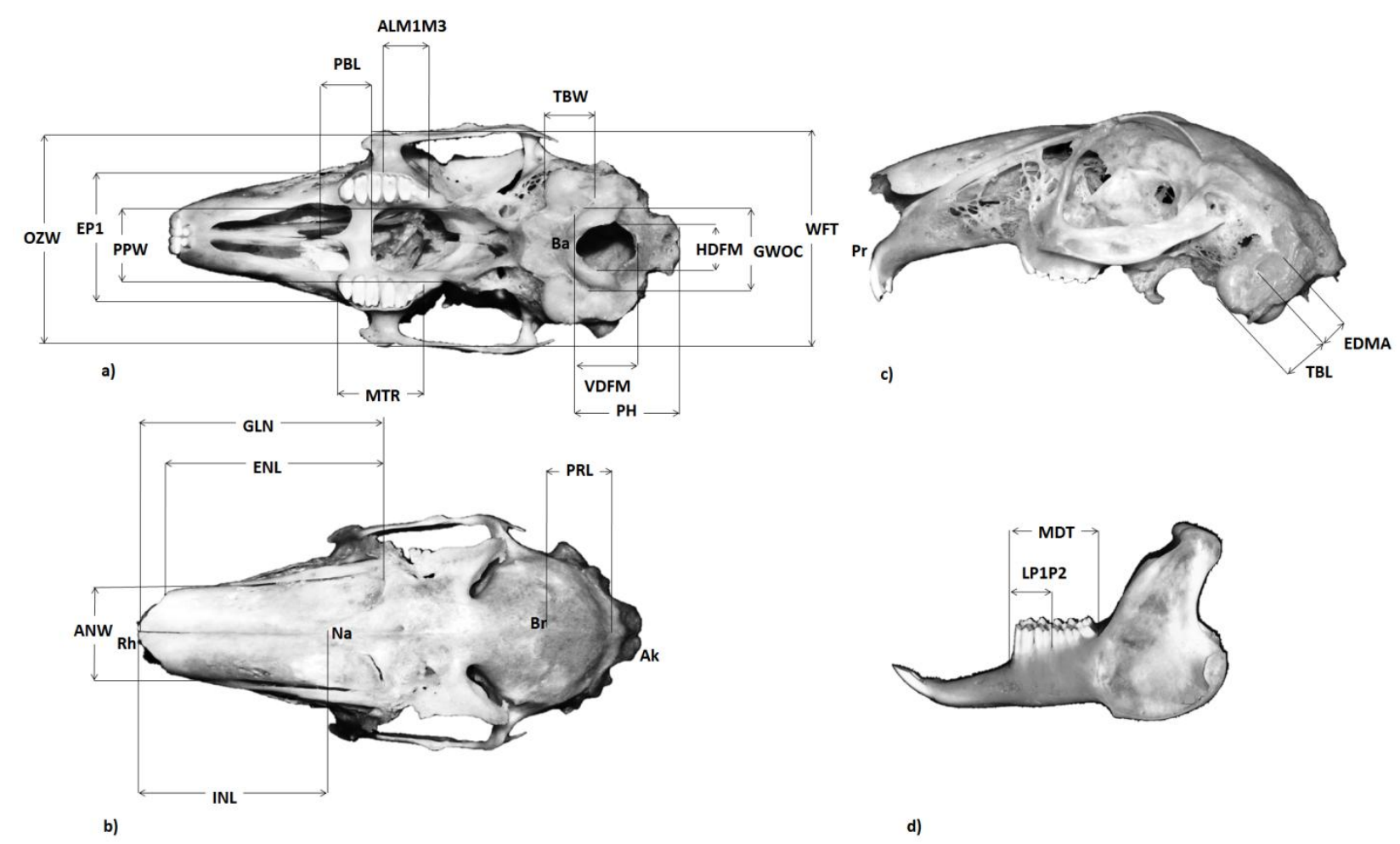

Figure 2. Craniometric measurements of the European brown hare (Lepus europaeus Pallas, 1778): a) ventral projection of the skull, b) dorsal projection of the skull, c) lateral projection of the skull, d) lateral projection of the mandible. Abbreviations: MTR - length of the tooth row in the maxilla; ALM1M3 - distance between anterior edge of $\mathrm{M}^{1}$ and posterior edge of $\mathrm{M}^{3}$ in the maxilla; EP1 external distance of $\mathrm{P}^{1}$ in the maxilla; WFT - external distance of facial tubercles; GWOC - greatest width of the occipital condyle; HDFM - width of foramen magnum; VDFM - height of foramen magnum; OZW - oral zygomatic width; PPW - post-palatine width (distance between $\mathrm{M}^{3}$ in the maxilla); TBL - length of bulla tympanica; TBW - width of bulla tympanica; EDMA - external length of meatus acusticus; PBL - length of palatine bridge; ENL - external nasal length; INL internal nasal length; ANW - anterior nasal width; GLN - greatest nasal length; PRL - parietal length;

$\mathrm{PH}$ - posterior cranial height; MDT - length of the tooth row in the mandible;

LP1P2 - distance between anterior edge of $\mathrm{P}_{1}$ and posterior edge of $\mathrm{P}_{2}$ in the mandible.

\section{Statistical analyses of craniometric measurements}

Prior to any analyses, collected data were checked for normality with the Kolmogorov-Smirnov test. Data were first log-transformed, to account for scaling of variances with the mean (BOOKASTEIN et al., 1985).

Analysis of variance (ANOVA) was performed to test the effect of population on craniometric measurements (STATSOFT INC., 2013).

To reduce the number of variables to a smaller number of representative and uncorrelated factors, principal component analysis (PCA) based on a correlation matrix was performed (DYTHAM, 2011). Only the first two principal components were used for this study, since they explain more than $50 \%$ of variation.

Canonical discriminant analysis was performed on craniometric measurements in order to find the optimal position of individuals in the space defined by discriminant axes. Pairwise comparisons were performed using squared Mahalanobis distances, which represent the distances of a case from the centroid in multidimensional space, defined by correlated independent variables. Larger differences of the squared Mahalanobis distances indicate 
greater separation between respective groups (EVERITT and HOTHORN, 2011; STATSOFT INC., 2013).

All analyses were done using Statistica version 10.0 (STATSOFT INC., 2011).

\section{RESULTS AND DISCUSSION}

Analysis of variance (ANOVA) showed significant effect of population on craniometric measurements (Wilks' $\lambda=0.07 ; F=2.15 ; \mathrm{p}<0.01$ ). Significant effect of population was found for 14 craniometric measurements (Table 1).

Table 1. Analysis of variance (ANOVA) of the craniometric measurements of the European brown hare (Lepus europaeus Pallas, 1778). Statistically significant differences $(\mathrm{p}<0.05)$ are indicated in bold. Abbreviations as in Fig. 2.

\begin{tabular}{c|cc}
\hline $\begin{array}{c}\text { Craniometric } \\
\text { measurement }\end{array}$ & F-value & P-value \\
\hline MTR & $\mathbf{8 . 4 2}$ & $\mathbf{0 . 0 0}$ \\
ALM1M3 & $\mathbf{3 . 5 6}$ & $\mathbf{0 . 0 1}$ \\
EP1 & $\mathbf{3 . 9 2}$ & $\mathbf{0 . 0 1}$ \\
WFT & $\mathbf{2 . 6 0}$ & $\mathbf{0 . 0 4}$ \\
GWOC & 1.02 & 0.40 \\
HDFM & 1.50 & 0.21 \\
VDFM & 1.07 & 0.38 \\
OZW & $\mathbf{2 . 9 3}$ & $\mathbf{0 . 0 3}$ \\
PPW & $\mathbf{6 . 1 1}$ & $\mathbf{0 . 0 0}$ \\
TBL & 0.53 & 0.71 \\
TBW & 1.99 & 0.11 \\
EDMA & 2.14 & 0.09 \\
PBL & $\mathbf{1 1 . 1 2}$ & $\mathbf{0 . 0 0}$ \\
ENL & $\mathbf{3 . 3 0}$ & $\mathbf{0 . 0 2}$ \\
INL & $\mathbf{3 . 8 8}$ & $\mathbf{0 . 0 1}$ \\
ANW & $\mathbf{2 . 8 7}$ & $\mathbf{0 . 0 3}$ \\
GLN & $\mathbf{3 . 0 4}$ & $\mathbf{0 . 0 2}$ \\
PRL & $\mathbf{4 . 1 0}$ & $\mathbf{0 . 0 0}$ \\
PH & 1.71 & 0.16 \\
MDT & $\mathbf{2 . 9 9}$ & $\mathbf{0 . 0 2}$ \\
LP1P2 & $\mathbf{2 . 6 4}$ & $\mathbf{0 . 0 4}$ \\
\hline
\end{tabular}

Principal component analysis (PCA) showed that the first two principal components accounted for $50.46 \%$ of variation (PC-I: $39.78 \%$; PC-II: $10.68 \%$ ). Highest contributions to PC-I, which represents the principal component related to cranial size, were made by the length of the tooth row in the maxilla (MTR), the external distance of facial tubercles (WFT), the oral zygomatic width (OZW), the external nasal length (ENL), the internal nasal length (INL), the greatest nasal length (GLN), the length of the tooth row in the mandible (MDT) and the distance between anterior edge of $\mathrm{P}_{1}$ and posterior edge of $\mathrm{P}_{2}$ in the mandible (LP1P2). On PC-II, highest contribution was found for the width of foramen magnum (HDFM), the height of foramen magnum (VDFM) and the posterior cranial height (PH) (Table 2). This analysis showed that populations from Stragari and Knić (closed habitats) had the smallest cranial size, while the population from Čelarevo (intermediate habitat) had the largest cranial size (Fig. 3). 
Table 2. Contributions of craniometric measurements of the European brown hare (Lepus europaeus Pallas, 1778) to the first two principal components (PC-I and PC-II).

Contributions larger than 0.80 are indicated in bold. Abbreviations as in Fig. 2.

\begin{tabular}{c|cc}
\hline $\begin{array}{c}\text { Craniometric } \\
\text { measurement }\end{array}$ & PC-I & PC-II \\
\hline MTR & $\mathbf{- 0 . 8 8}$ & 0.05 \\
ALM1M3 & -0.76 & 0.24 \\
EP1 & -0.77 & 0.13 \\
WFT & $\mathbf{- 0 . 8 2}$ & 0.12 \\
GWOC & -0.33 & -0.69 \\
HDFM & -0.19 & $\mathbf{- 0 . 8 1}$ \\
VDFM & 0.01 & -0.70 \\
OZW & $\mathbf{- 0 . 8 6}$ & 0.01 \\
PPW & -0.66 & -0.04 \\
TBL & -0.31 & -0.17 \\
TBW & -0.09 & -0.04 \\
EDMA & 0.01 & -0.08 \\
PBL & -0.26 & -0.10 \\
ENL & $\mathbf{- 0 . 9 1}$ & -0.02 \\
INL & $\mathbf{- 0 . 8 0}$ & -0.06 \\
ANW & -0.65 & 0.27 \\
GLN & $\mathbf{- 0 . 9 2}$ & 0.01 \\
PRL & -0.19 & -0.08 \\
PH & -0.34 & -0.60 \\
MDT & $\mathbf{- 0 . 8 5}$ & -0.01 \\
LP1P2 & $\mathbf{- 0 . 8 1}$ & 0.17 \\
\hline
\end{tabular}

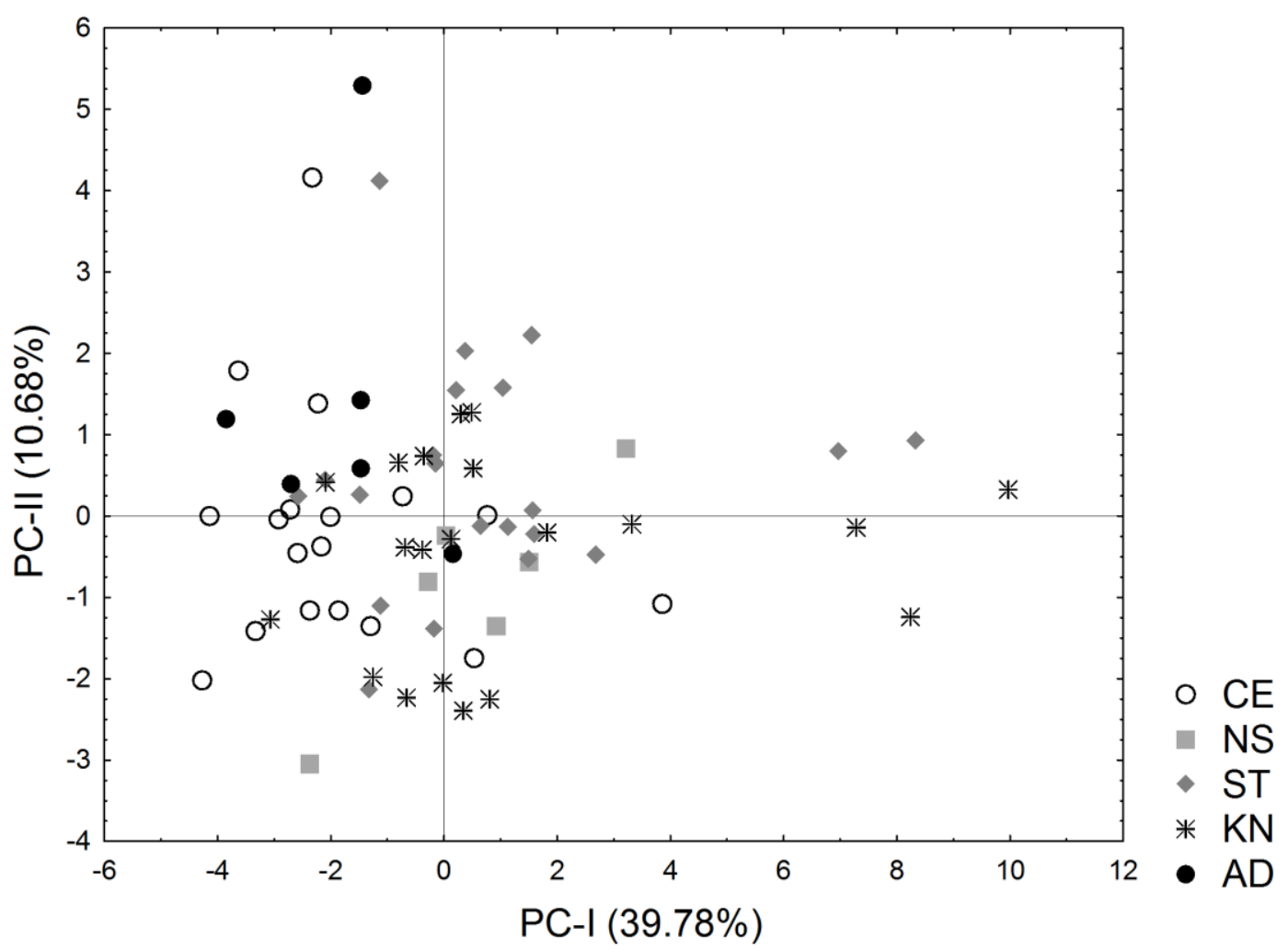

Figure 3. Principal component analysis (PCA) of the European brown hare (Lepus europaeus Pallas, 1778) populations. Scatter plot of factor loadings for PC-I against PC-II. Abbreviations as in Fig. 1. 
Canonical discriminant analysis indicated that the craniometric measurements that mostly contributed to the discrimination between populations were the length of palatine bridge (PBL) (Wilks' $\lambda=0.13 ; \mathrm{F}=11.90 ; \mathrm{p}<0.01$ ) which was the highest in individuals from Novi Sad, the parietal length (PRL) (Wilks' $\lambda=0.09 ; \mathrm{F}=3.71 ; \mathrm{p}=0.01)$ and the length of the tooth row in the maxilla (MTR) (Wilks' $\lambda=0.08 ; \mathrm{F}=2.15 ; \mathrm{p}=0.09$ ) which were the highest in individuals from Čelarevo. Population from Čelarevo also had the highest values of the oral zygomatic width (OZW). Individuals from Stragari and Knić had higher values of the posterior cranial height (PH) and the width of bulla tympanica (TBW) compared to others. Individuals from Knić and Ada had higher values of the greatest nasal length (GLN), the external distance of facial tubercles (WFT) and the greatest width of the occipital condyle (GWOC) compared to the other populations (Fig. 4). Individuals from Stragari had higher values of the distance between anterior edge of $\mathrm{P}_{1}$ and posterior edge of $\mathrm{P}_{2}$ in the mandible (LP1P2) and the distance between anterior edge of $\mathrm{M}^{1}$ and posterior edge of $\mathrm{M}^{3}$ in the maxilla (ALM1M3). In general, higher values of craniometric measurements were recorded in populations from Čelarevo and Novi Sad, while the population from Knić had the smallest cranial size. When observing squared Mahalanobis distances, population from Čelarevo did not differ significantly from the population from Novi Sad (Table 3). Populations from Novi Sad and Čelarevo differed significantly from populations from Stragari, Knić and Ada.

The results showed partial grouping of populations in accordance with the habitat type (open, intermediate and closed). Both populations from closed habitats (Stragari and Knić) had smaller skulls. However, when observing intermediate and open habitats, lesser differences existed, especially between individuals from Čelarevo (intermediate habitat) and Novi Sad (open habitat). This can be the result of geographical non-isolation between these two populations or the result of reintroductions of individuals from one population to another. In general, common characteristic of individuals from both intermediate and open habitat are higher values of cranial traits. Moreover, craniometric measurements had lower values in southern compared to northern populations, which is in accordance with earlier findings that cranial size of Lepus is related to latitude (PALACIOS, 1996; PINTUR et al., 2014).

Table 3. Canonical discriminant analysis of the differences between analyzed European brown hare (Lepus europaeus Pallas, 1778) populations. Values above diagonal represent F-values, values below diagonal represent squared Mahalanobis distances (with statistically significant differences of $p<0.05$ indicated in bold). Abbreviations as in Fig. 1.

\begin{tabular}{c|ccccc}
\hline Population & CE & NS & ST & KN & AD \\
\hline CE & $*$ & 1.26 & 3.67 & 6.16 & 1.85 \\
NS & 8.45 & $*$ & 2.38 & 4.16 & 2.06 \\
ST & $\mathbf{1 1 . 4 0}$ & $\mathbf{1 5 . 3 4}$ & $*$ & 1.63 & 1.04 \\
KN & $\mathbf{1 9 . 5 8}$ & $\mathbf{2 7 . 1 4}$ & 4.79 & $*$ & 1.30 \\
AD & $\mathbf{1 2 . 3 7}$ & $\mathbf{2 0 . 7 0}$ & 6.69 & 8.51 & $*$ \\
\hline
\end{tabular}

The results showed higher values of the length of the tooth row in the maxilla and the oral zygomatic width in individuals from Čelarevo (intermediate habitat). This indicates foraging activities and food type probably influence cranial traits of the European brown hare. In Čelarevo, individuals forage not only at agricultural fields, but also at abandoned agricultural areas with autochthonous steppe vegetation or at flooded plains. Zygomatic arches are the attachment places for the strong masticatory muscles which are more developed in individuals inhabiting areas with many plant species which require intense mechanical processing, as seen in other herbivores, such as roe deer (MiLOŠEVIĆ-ZLATANOVIĆ et al., 2016). 
Individuals from Knić (closed habitat) differed the most from individuals from Novi Sad (open habitat) by higher values of the cranial traits of the occipital region. In closed habitats, where vegetation is dense, occipital region is well-developed due to strong neck muscles involved in tilting the head (ZоTTI et al., 2009), allowing better habitat visibility and maintaining balance during locomotion. Similar to individuals from Knić, but to a lesser extent, individuals from Stragari had well developed occipital region. Additionally, these individuals had higher values of the premolar length in the mandible, again indicating that foraging activities differ between habitat types. The results also indicated slightly larger auditory bulla in closed habitats, suggesting the importance of hearing in spotting potential predators.

These preliminary results suggest that differentiation of populations in accordance with habitat type does exist in European brown hare, and that further analyses on greater sample size and number of populations are needed to understand the influence of habitat conditions on cranial variability of this species.

It must be noted that introductions and reintroductions of individuals from different habitats can strongly influence the obtained results (MILOŠEVIĆ-ZLATANOVIĆ, 2016; JEREMIĆ, 2016). Introduced individuals usually cannot survive in different habitat type from the one they are introduced from, mainly becoming subjective to predators and diseases. This is one of the reasons many introductions are unsuccessful and one of the important factors for the declining population numbers of European brown hare. However, the existence of differentiation according to habitat type obtained in this study indicates that, despite constant introductions and reintroductions of individuals from different habitats, individuals that mostly survive must be adapted to local habitat conditions.

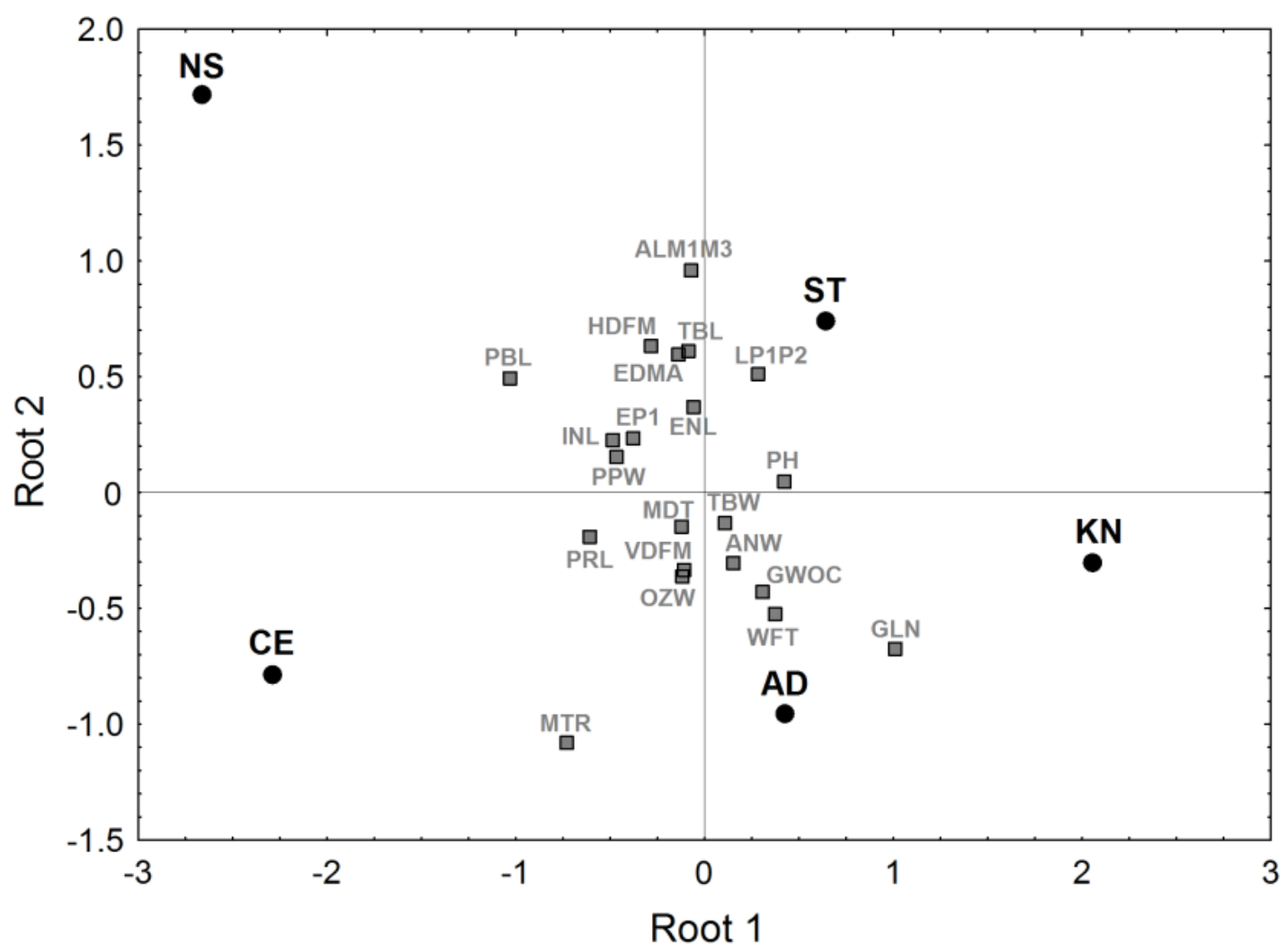

Figure 4. Canonical discriminant analysis of the five European brown hare (Lepus europaeus Pallas, 1778) populations. Abbreviations as in Figs. 1 and 2. 
Presented results are of great importance in understanding the ecology and improving hunting management of European brown hare populations. As the size of its populations is decreasing due to the lack of proper habitat, the impact of predators, diseases, uncontrolled introductions and reintroductions and other factors, further research is needed to fully identify the causes that lead to reduction of population numbers and to implement adequate conservation measures.

\section{Acknowledgments}

This study was funded by the Ministry of Agriculture, Forestry and Water Management of the Republic of Serbia (Grant No. 401-00-03708/2018-10) to SMZ and MJ.

\section{References:}

[1] BaKer, A.J., Peterson, R.L., Eger, J.L., Manning, T.H. (1978): Statistical analysis of geographic variation in the skull of the arctic hare (Lepus arcticus). Canadian Journal of Zoology 56: 2067-2082. doi: 10.1139/z78-280

[2] Bookstein, F.L., Chernoff, B., Elder, R.L., Humphries, J.M., Smith. G.R., STRAUSS, R.E. (1985): Morphometrics in evolutionary biology. The geometry of size and shape change, with examples from fishes. Special Publication 15. The Academy of Natural Sciences of Philadelphia.

[3] Boudet, C. (2010): Mammals’ Planet: Vs nº - Brown Hare or European Hare, Conejo - Species Sheet

http://www.planet-mammiferes.org/drupal/en/node/38?indice=Lepus+europaeus Accessed 17 May 2016.

[4] CABOŃ-RACZYŃSKA, K. (1964b): Studies on the Europaean hare. III. Morphological variation of the skull. Acta Theriologica 9: 249-285. doi: 10.4098/AT.arch.64-33

[5] CABOŃ-RACZYŃSKA, K. (1964a): Correlations of skull measurements of Lepus europaeus Pallas, 1778. Acta Theriologica 8: 207-216. doi: 10.4098/AT.arch.64-13

[6] Danilović, M., GaČıć, D. (2014): Sustainable use of forest and hunting resources. Bulletin of the Faculty of Forestry 2014: 25-50. doi: 10.2298/GSF14S1025D

[7] Demirbaş, Y., AlbayraK, I. (2014): The taxonomic status and geographic distribution of the Europaean hare (Lepus europaeus Pallas, 1778) in Turkey (Mammalia: Lagomorpha). Tirkish Journal of Zoology 38: 119-130. doi: 10.3906/zoo1212-6

[8] Dytham, C. (2011): Choosing and using statistics: a biologist's guide. $3^{\text {rd }}$ ed. WileyBlackwell, Chichester.

[9] EVERITT, B., HOTHORN, T. (2011): An introduction to applied multivariate analysis in $R$. Springer-Verlag, New York.

[10] Flux, J.E.C., Angermann, R. (1990): The hares and jackrabbits. In: Chapman, J.A., Flux, J.E.C. (eds). Rabbits, hares and pikas - status survey and conservation action plan. IUCN, Gland, Switzerland. pp. 61-94.

[11] Ge, D.Y, YaO, L., XIA, L., Zhang, Z., YANG, Q. (2015): Geometric morphometric analysis of skull morphology reveals loss of phylogenetic signal at the generic level in 
extant lagomorphs (Mammalia: Lagomorpha). Contributions to Zoology 84: 267-284. doi: 10.1163/18759866-08404001

[12] Hirakawa, H., Kuwahata, T., Shubata, Y., Yamade, E. (1992): Insular variation of the Japanese Hare (Lepus brachyurus) on the Oki Islands, Japan. Journal of Mammalogy 73: 672-679. doi: 10.2307/1382042

[13] Hoffman, R.S., Smith, A.T. (2005): Order Lagomorpha. In: Willson, D.E., Reeder, D.M. (eds). Mammal species of the world - a taxonomic and geographic reference. JHU Press, Baltimore. pp. 185-211.

[14] Jeremić, N. (2016): Craniometric differentiation of the European brown hare (Lepus europaeus Pallas 1778) across different habitats in Serbia. Diploma paper. Faculty of Science, University of Kragujevac, Kragujevac. [in Serbian]

[15] Koyabu, D., Werneburg, I., Morimoto, N., Zollikofer, C.P.E., Forasiepi, A.M., Endo, H., Kimura, J., OHDACHI, S.D., Son, N.T., SÁNCHEZ-VillagRA, M.R. (2014): Mammalian skull heterochrony reveals modular evolution and a link between cranial development and brain size. Nature Communications 5: 3625 . doi: $10.1038 /$ ncomms 4625

[16] Martino, V. (1935): Građa za sistematiku jugoslovenskih zečeva. Lovac 40: 213-215.

[17] MiloŠEviĆ-Zlatanović, S. (2016): Problemi u gazdovanju populacijama zeca (Lepus europaeus Pall.) i poljske jarebice (Perdix perdix L.) u lovištima Centralne Srbije. 8. međunarodni sajam lova, ribolova, lovnog turizma $i$ nautike 26.-29. May 2016 (invitation lecture).

[18] Milošević-Zlatanović, S., Tomašević Kolarov, N., Vukov, T., Stamenković, S. (2016): Correlation pattern in roe deer cranium: sexual dimorphism across different habitats. Journal of Zoology 300: 291-304. doi:10.1111/jzo.12383

[19] NAGORSEN, D.W. (1985): A morphometric study of geographic variation in the snowshoe hare (Lepus americanus). Canadian Journal of Zoology 63: 567-579. doi: 10.1139/z85-083

[20] NowAK, R.M. (1999): Walker's mammals of the world. $6^{\text {th }}$ ed. The John Hopkins University Press, Baltimore.

[21] Palacios, F., Angelone, G., Alonso, S., Reig, S. (2008): Morphological evidence of species differentiation within Lepus capensis Linneaus, 1758 (Leporidae, Lagomorpha) in Cape Province, South Africa. Mammalian Biology 73: 358-370. doi: 10.1016/j.mambio.2007.10.013

[22] Palacios, G. (1996): Systematic of the indigenous hares of Italy traditionally identified as Lepus europaeus Pallas, 1778 (Mammalia: Leporidae). Bonn Zoological Bulletin 46: 59-91.

[23] Pintur, K., Dančević, N., Štedul, I., Popović, N., SlijepČević, V. 2014. Craniometric features of Europaean hare (Lepus europaeus Pall.) from North-west Croatia and the island of Vir. Veterinarski arhiv 84: 387-400.

[24] Riga, F., Trocchi, E., Randi, E., Toso, S. (2001): Morphometric differentiation between the Italian hare (Lepus corsicanus De Winton, 1897) and the European brown hare (Lepus europaeus Pallas, 1778). Journal of Zoology 253: 241-252. doi: 10.1017/S0952836901000218

[25] Shevchenko, L.S., Peskov, V.N. (2005): The geographical variability and morphological differentiation of the European hare on the territory of Ukraine. Proceedings of Zoological Museum 37: 121-133. 
[26] SlameČKA, J., Hell, R., JURČIK, R. (1997): Brown hare in the Westslovak Lowland. Acta Scientarum Naturalium Brno 31: 21-28, 100-103.

[27] StATSOFT InC. (2011): STATISTICA for Windows, version 10.0. Tulsa.

[28] StatSoft Inc. (2013): Electronic statistics textbook. Tulsa, OK. http://www.statsoft.com/textbook/ Accessed 5 June 2016.

[29] Thompson, P. (2010): Conserving the brown hare. Game and Wildlife Conservation Trust. Hampshire.

[30] VAPA, M., ŠELMIĆ, V. 1997. Sadašnje stanje i budućnost evropskog zeca. Simpozijum: Zec i jarebica u savremenim agroekosistemima. Novi Sad. pp. 41-51.

[31] WinCENTZ JENSEN, T.-L. (2009): Identifying causes for population decline of the brown hare (Lepus europaeus) in the agricultural landscapes in Denmark. PhD thesis. Aarhus Univerity, Aarhus.

[32] XIN, L. (2003): Postnatal growth of skull linear measurements of Cape hare Lepus capensis in northern China: an analysis in an adaptive context. Biological Journal of Linnean Society 78: 343-353. doi: 10.1046/j.1095-8312.2003.00145.x

[33] Yom-Tov, Y., GEFFEN, E. (2006): Geographic variation in body size: the effects of ambient temperature and percipitation. Oecologia 148: 213-218. doi: 10.1007/s00442006-0364-9

[34] ZotTi, A., BenZato, T., Cozzi, B. (2009): Cross-sectional anatomy of the rabbit neck and trunk: Comparison of computed tomography and cadaver anatomy. Research in Veterinary Science 87: 171-176. doi: 10.1016/j.rvsc.2009.02.003 